\title{
Pannus, thrombus, calcium-Bioprosthetic mitral replacement in young children has it all
}

\author{
Ronald K. Woods, MD, PhD, and Viktor Hraska, MD, PhD
}

\footnotetext{
From the Division of Pediatric Cardiothoracic Surgery, Department of Surgery, Medical College of Wisconsin; and Herma Heart Center, Children's Hospital of Wisconsin, Milwaukee, Wis.

Disclosures: Authors have nothing to disclose with regard to commercial support.

Received for publication Sept 21, 2017; accepted for publication Sept 27, 2017; available ahead of print Nov 7 , 2017.

Address for reprints: Ronald K. Woods, MD, PhD, Department of Surgery Medical College of Wisconsin, Division of Pediatric Cardiothoracic Surgery, Children's Hospital of Wisconsin, 9000 W Wisconsin Ave, MS B 730, Milwaukee, WI 53226 (E-mail: rwoods@chw.org).

J Thorac Cardiovasc Surg 2018;155:753-4

$0022-5223 / \$ 36.00$

Copyright (c) 2017 by The American Association for Thoracic Surgery

https://doi.org/10.1016/j.jtcvs.2017.09.127
}

In this issue of the Journal, Gellis and colleagues ${ }^{1}$ present a cohort of 31 children younger than 5 years with bioprosthetic mitral valve replacement (MVR), excluding valve-in-stent options. They report rereplacement in $32 \%$ of patients at a median follow-up of 10.5 months. They performed histologic evaluation of 13 valves ( 8 of the 10 replaced valves, 4 from autopsy, and 1 after transplant), clearly depicting the roles predominantly of pannus but also of thrombus and calcification as factors underlying stenosis of the prostheses. The only factor related to prosthesis failure was age at the time of replacement-not new news.

In a 2008 report $^{2}$ from the authors' institution of a cohort of 118 patients younger than 5 years with mechanical MVR, 86 valves were size $19 \mathrm{~mm}$ or smaller. Freedom from redo MVR was approximately $90 \%$ at 2 years. This finding is consistent with other published data from similar age cohorts and mechanical replacement, with freedom from redo MVR ranging from $85 \%$ to $100 \%$ at 1 year of follow-up. ${ }^{3-7}$ In the cohort of Gellis and colleagues, ${ }^{1} 22$ of 31 valves were size $19 \mathrm{~mm}$ or larger, with a much lower freedom from redo MVR.

Mitral replacement in the young child remains a formidable problem for our specialty. The need for replacement typically implies bad anatomy, previous exhaustive repair attempts, a labile pulmonary vascular bed, limited annular size, and a challenging overall clinical situation. Dacron polyester fabric skirt extension and supra-annular placement have not solved the problem. Results from the HALO trial of the St Jude 15-mm mechanical prosthesis are forthcoming. ${ }^{8}$ Tubularized biologic material is another option with limited data at present. The report of Gellis and colleagues ${ }^{1}$ indicates that although a bioprosthetic option exists, it is not the solution to the problem. It is true that 27 patients were managed without warfarin, which can be a big advantage for certain patients; however, the early failure rate was high. Gellis and colleagues ${ }^{1}$ have championed alternative approaches as well, and presumably they will present their results with the valve-in-stent approach in a future report.

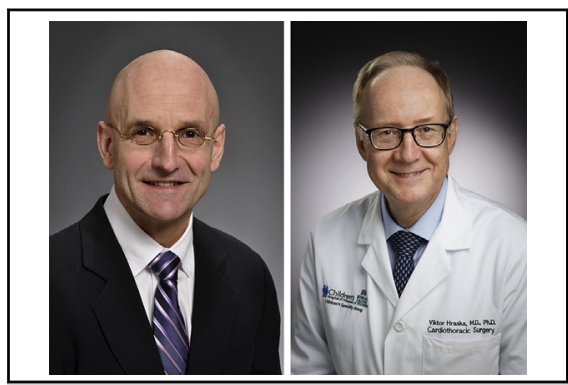

Ronald K. Woods, MD, PhD (left), and Viktor Hraska $\mathrm{MD}, \mathrm{PhD}$ (right)

\section{Central Message}

Among young children with bioprosthetic mitral replacement, early prosthesis failure occurs in a high percentage of patients.

See Article page 746 .
The demonstration of early thrombus and prosthesis failure raises an important concern with implications for the evolving valve-in-stent option. The literature on adult aortic valve replacement, both standard bioprosthetic and transcatheter valve-in-stent options, has documented early thrombus formation as a significant issue. ${ }^{9,10}$ For the bovine jugular stented valve in the mitral position, we currently bridge with heparin to warfarin anticoagulation and use aspirin, although our experience is limited. We would not be surprised if as a specialty we ultimately learn that all nonautologous materials in the mitral position in this age group would perform better with both anticoagulation and antiplatelet therapy-both unlikely to affect early calcification. If this is true, then there is no role for a commercially available bioprosthesis in this context. For the annulus that prohibits patient size-matched intra-annular placement of a 19-mm or larger mechanical valve, tubularized biologic material and valve-in-stent technology remain reasonable options. Otherwise, it would appear that a mechanical valve is still the best option. For the size permissible context, better prediction of which repaired valves are going to repeatedly fail with earlier replacement before multiple failed repairs impair physiology, avoidance of oversizing, and perhaps self-check international normalized ratio are potential options to improve outcomes with mechanical replacement. 


\section{References}

1. Gellis L, Baird CW, Emani S, Borisuk M, Gauvreau K, Padera RF, et al. Morphological and histological findings in bioprosthetic valves explanted from the mitral position in children younger than 5 years of age. J Thorac Cardiovasc Surg. 2018; 155:746-52.

2. Selamet Tierney ES, Pigula FA, Berul CI, Lock JE, del Nido PJ, McElhinney DB. Mitral valve replacement in infants and children 5 years of age or younger: evolution in practice and outcome over three decades with a focus on supra-annular prosthesis implantation. J Thorac Cardiovasc Surg. 2008;136:954-61. 961.e1-3.

3. Caldarone CA, Raghuveer G, Hills CB, Atkins DL, Burns TL, Behrendt DM, et al. Long-term survival after mitral valve replacement in children aged $<5$ years: a multi-institutional study. Circulation. 2001; 104(12 Suppl 1):I143-7.

4. Raghuveer G, Caldarone CA, Hills CB, Atkins DL, Belmont JM, Moller JH. Predictors of survival, growth, and functional status following mechanical mitral valve replacement in children aged $<5$ years, a multi-institutional study. Circulation. 2003;108(Suppl 1):I174-9.
5. Rafii DY, Davies RR, Carroll SJ, Quaegebeur JM, Chen JM. Age less than two years is not a risk factor for mortality after mitral valve replacement in children. Ann Thorac Surg. 2011;91:1228-34.

6. Vohra HA, Laker S, Stumper O, De Giovanni JV, Wright JG, Barron DJ, et al. Predicting the performance of mitral prostheses implanted in children under 5 years of age. Eur J Cardiothorac Surg. 2006;29:688-92.

7. Beierlein W, Becker V, Yates R, Tsang V, Elliott M, de Leval M, et al. Long-term follow-up after mitral valve replacement in childhood: poor event-free survival in the young child. Eur J Cardiothorac Surg. 2007;31:860-5.

8. HALO: A single arm prospective investigation of the SJM ${ }^{\mathrm{TM}}$ Masters $\mathrm{HP}^{\mathrm{TM}}$ $15 \mathrm{~mm}$ rotatable mechanical heart valve; clinicaltrials.gov identifier NCT02097420. Available at: https://clinicaltrials.gov/ct2/show/NCT02097420. Accessed September 18, 2017.

9. Mack M, Holmes D. Bioprosthetic valve thrombosis: the harder one looks, the more one finds. J Thorac Cardiovasc Surg. 2016;152:952-3.

10. Yahagi K, Torii S, Ladich E, Kutys R, Romero ME, Mori H, et al. Pathology of selfexpanding transcatheter aortic valves: findings from the CoreValve US pivotal trials. Catheter Cardiovasc Interv. September 12, 2017 [Epub ahead of print]. 